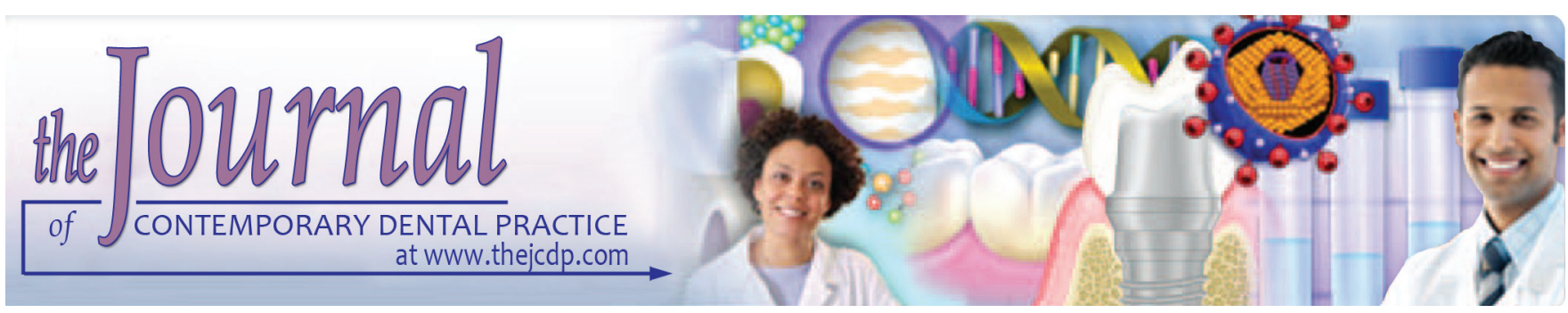

\title{
Prevalence of Dental Caries and Oral Hygiene Status among Juvenile Prisoners in the Kingdom of Saudi Arabia
}

Thamer Alkhadra

\begin{abstract}
Aim: The aim of the study was to determine the prevalence of dental caries and oral hygiene status among juvenile prisoners in Riyadh, Kingdom of Saudi Arabia.

Materials and methods: A total of 105 prisoners aged between 12 and 17 years of age from the Juvenile Detention Center were included in the study. Any prisoner with systemic illness and being noncooperative were excluded from the study. Clinical examinations were performed under an artificial light source using a disposable mouth mirror and explorer while seated on a portable chair. The dental caries experience was measured as the number of decayed, missing, or filled permanent teeth (DMFT) using DMFT score. The oral hygiene index $(\mathrm{OHI})$ was assessed by the Greene and Vermillion method. The data collected were analyzed using Statistical Package for the Social Sciences version 16.
\end{abstract}

Results: The mean age of the sample was 16.33 years, with $74.3 \%$ of the prisoners in the 16 to 17-year-old group. The dental caries index measured by calculating the mean DMFT of the juvenile prisoners increased with age. The DMFT scores of 9.09 (4.388) for 78 juvenile prisoners aged 16 to 17 years followed by 9.00 (2.925) for 19 prisoners aged 14 to 15 years and 7.13 (1.808) for 8 prisoners aged 12 to 13 years were observed. The oral hygiene status of the prisoners showed that more than half of the juvenile prisoners included in the study had poor (53.3\%) oral hygiene and less than half had fair ( $45.7 \%$ ) oral hygiene and only one participant demonstrated good oral hygiene.

Conclusion: The juvenile prisoners had high prevalence of dental caries and fair-to-bad oral hygiene, indicating poor oral health status. Furthermore, the study emphasizes the need for special attention from the concerned health authorities, voluntary organizations, and surrounding dental colleges in meeting the oral health needs of this group.

Department of Pediatric Dentistry and Orthodontics, College of Dentistry, King Saud University, Riyadh, Kingdom of Saudi Arabia

Corresponding Author: Thamer Alkhadra, Department of Pediatric Dentistry and Orthodontics, College of Dentistry, King Saud University, Riyadh, Kingdom of Saudi Arabia, e-mail: thamer@ksu.edu.sa
Clinical significance: The study provides an important database for decision makers to take on the challenge of reducing dental caries among juvenile prisoners.

Keywords: Decayed missing and filled teeth, Dental caries, Juvenile prisoners.

How to cite this article: Alkhadra T. Prevalence of Dental Caries and Oral Hygiene Status among Juvenile Prisoners in the Kingdom of Saudi Arabia. J Contemp Dent Pract 2017;18(11):991-995.

\section{Source of support: Nil}

Conflict of interest: None

\section{INTRODUCTION}

Juvenile delinquency (or juvenile offending) is participation of minors less than 18 years of age in illegal behavior. A juvenile alleged to have breached the law is called a "delinquent juvenile." The juvenile criminal offence is increasing day-by-day and is one of the major issues faced by the present world. These are also a truly neglected group as there is no proper care for their health and well-being. ${ }^{1,2}$

The delinquent juveniles in the detention center are considered a high-risk population because these groups in most of the cases have unmet health issues, such as physical, developmental, and psychological. These health issues are found to be more in delinquent juveniles compared with that of the general population and could also pose a risk for research to be conducted in the detention centers. ${ }^{3}$ It has been reported that various stress factors, such as low educational level, lower socioeconomic background, unemployment, overcrowding, hostility, and discrimination could impact the physical and psychological health of this group of people. ${ }^{4-7}$

Good oral health is very essential for overall wellbeing and determines the quality-of-life of children, adults, and the aged. A poor oral health can affect nutrition, growth, and development in children, and could have a negative 
effect on routine activities of adults. ${ }^{8}$ Dental caries and periodontal diseases are the most prevalent oral health concerns affecting the society. ${ }^{9}$ Though these ailments are not life-threatening, the sequel of pain and annoyance they cause needs serious consideration. ${ }^{10}$ The socioeconomic factor is the predisposing factor in the development of both these ailments. Furthermore, low income and poor education have found to influence the occurrence of both dental caries and periodontal disease. ${ }^{11,12}$

The greatest impact of oral diseases is seen on the underprivileged and socially marginalized populations compared with the general populations. The prevalence and severity of oral disease is high in socially deprived groups, such as the prisoners. Previous epidemiological studies on oral health of prisoners have concentrated on adults and the aged. The information about oral health of incarcerated children and adolescents is scarce. ${ }^{2,13}$ Prisoners are constrained with poor general and oral health. The main reason for prisoners to seek medical care is the oral and dental problems, and this also explains why they are referred outside the prison for treatment. ${ }^{14-16}$

In drafting effective strategies to prevent oral disease and promote oral health of incarcerated children and adolescents, the epidemiological information on major oral diseases remains crucial. ${ }^{17}$ Numerous studies have been done to study the prevalence of dental caries and oral hygiene status among the general population in the Kingdom of Saudi Arabia. ${ }^{18-22}$ Epidemiological data on incarcerated children and adolescents are lacking. Hence, the present study was designed to determine the prevalence of dental caries and oral hygiene status in incarcerated children and adolescents of the Juvenile Detention Center of Riyadh, Kingdom of Saudi Arabia.

\section{MATERIALS AND METHODS}

\section{Ethical Approval}

The present study was in accordance with the ethical standards as laid down in the 1964 Declaration of Helsinki and its later amendments. The study was approved by the ethical committee at College of Dentistry Research Centre, King Saud University with registration number (IR 0069/ 2013). Also, the permission to conduct the research at the detention facility was obtained by the Juvenile Detention Center through the Ministry of Social Affairs. In accordance with the ethical approval, a written informed consent was obtained from the participant after the details and purpose of the study were described verbally.

\section{Oral Examination}

A total of 105 male prisoners aged 12 to 17 years from one of the juvenile detention centers in Riyadh, Kingdom of Saudi Arabia, participated in the study. Any participant who was noncooperative and suffering from systemic illness was excluded from the study. The participants completed a structured interview to determine the health status and behaviors as well as apparent oral health needs, before undergoing an oral examination.

The oral examination to assess the dental caries and oral hygiene status was carried out over 4 days with 25 subjects as the maximum number for the first 3 days and 30 participants on the last day. The examiner entered the data on the predesigned questionnaire, which contained questions on name, age, oral hygiene practices, reason for imprisonment, duration of imprisonment, and the availability and utilization of dental health care facilities in the prison.

After completion of questionnaires, clinical examinations were performed on the participants seated on a portable chair by a single examiner under an artificial light source using a mouth mirror and a standard explorer. The dental caries incidence was measured using the DMFT index [following the World health Organization's (WHO) guidelines]. ${ }^{23}$ In the DMFT index, D represents the number of teeth with decay that requires treatment, $M$ represents the number of missing teeth that have been extracted due to caries, and $F$ represents the number of teeth with filling (restorations). A DMFT score of 0 to 2 was considered as low caries incidence, a score of 3 to 5 was considered as moderate caries incidence, and a score equal or higher than 6 was considered as high incidence of caries. $^{23}$

The oral hygiene status was assessed using the simplified oral hygiene index (OHI-S) as described by Greene and Vermillion. ${ }^{24}$ The six surfaces (four posterior and two anterior teeth) were examined for the OHI-S. The first fully erupted tooth distal to the second premolar, usually the first molar, was examined. If the first molar is missing, the second molars were examined. The buccal surfaces of the maxillary molars and the lingual surfaces of the mandibular molars were examined. In the anterior teeth, the labial surfaces of the maxillary right and the lingual surface of mandibular left central incisors were examined. If either of the anterior teeth was missing, the incisor on the opposite arch was examined. Based on the examination of tooth surfaces, the debris (DI-S) and calculus index (CI-S) scores were recorded and calculated. The OHI-S index was determined by summing up the DI-S and CI-S indices. A total $\mathrm{OHI}$ score of 0.0 to 1.2 was considered as good, 1.3 to 3.0 as fair, and 3.1 to 6.0 as poor.

\section{Statistical Analysis}

The data collected were analyzed using the Statistical Package for Social Sciences Version 16.0 program for Windows (SPSS Inc., Chicago, Illinois, USA) to generate 
Prevalence of Dental Caries and Oral Hygiene Status among Juvenile Prisoners in the Kingdom of Saudi Arabia

Table 1: Distribution of juvenile prisoners according to age

\begin{tabular}{lll}
\hline Age (years) & $n$ & Percentage \\
\hline $12-13$ & 8 & 7.6 \\
$14-15$ & 19 & 18.1 \\
$16-17$ & 78 & 74.3 \\
\hline Total & 105 & 100 \\
\hline
\end{tabular}

Table 2: Reasons for imprisonment of the juvenile prisoners

\begin{tabular}{lll}
\hline Reasons & Number & Percentage \\
\hline Fighting & 21 & 20 \\
Theft & 40 & 38.1 \\
Drugs & 10 & 9.5 \\
Other reasons & 34 & 32.4 \\
\hline Total & 105 & 100 \\
\hline
\end{tabular}

Table 3: Distribution of mean (SD) DMFT in relation to age of juvenile prisoners

\begin{tabular}{llllll}
\hline & & & & \multicolumn{2}{c}{ 95\% confidence interval for mean } \\
\cline { 5 - 6 } Age (years) & $n(\%)$ & Mean $(S D)$ & Standard error & Lower bound & Upper bound \\
\hline $12-13$ & $8(7.6)$ & $7.13(1.808)$ & 0.639 & 5.61 & 8.64 \\
$14-15$ & $19(18.1)$ & $9.00(2.925)$ & 0.671 & 7.59 & 10.41 \\
$16-17$ & $78(74.3)$ & $9.09(4.388)$ & 0.497 & 8.10 & 10.08 \\
\hline Total & $105(100)$ & $8.92(4.028)$ & 0.393 & 8.14 & 9.70 \\
\hline
\end{tabular}

Table 4: Distribution of mean (SD) DI-S, CI-S, and OHI-S in relation to age of juvenile prisoners

\begin{tabular}{llllll}
\hline Age (years) & $n$ & DI-S & Cl-S & OHI-S & Interpretation \\
\hline $12-13$ & 8 & $1.23 \pm 0.59$ & $1.68 \pm 0.35$ & $2.91 \pm 0.86$ & Fair \\
$14-15$ & 19 & $2.12 \pm 1.04$ & $2.27 \pm 1.2$ & $4.39 \pm 0.43$ & Poor \\
$16-17$ & 78 & $2.72 \pm 0.63$ & $3.02 \pm 0.55$ & $5.74 \pm 0.21$ & Poor \\
\hline
\end{tabular}

descriptive statistics. Coefficient of correlation was used to find any association between DMFT and OHI-S index values.

\section{RESULTS}

The mean age of the participants included in the study was 16.33 with $74.3 \%$ of the juveniles in the 16 to 17 year age group (Table 1). The major reason for imprisonment of juveniles was theft (38.1\%) and other various reasons (32.4\%; Table 2).

The dental caries index measured by calculating the mean DMFT of the juvenile prisoners increased with age. This is reflected in the high percentage of mean [standard deviation (SD)] DMFT score of 9.09 (4.388) for 78 juvenile prisoners aged 16 to 17 years followed by 9.00 (2.925) for 19 prisoners aged 14 to 15 years and 7.13 (1.808) for 8 prisoners aged 12 to 13 years (Table 3 ). All the participants included in the study showed high incidence of caries irrespective of the age group.

The oral hygiene status of the prisoners in relation to age is presented in Table 4. As in DMFT, the mean OHI-S also increased with age. More than half of the juvenile prisoners included in the study had poor oral hygiene $(53.3 \%)$ and less than half had fair oral hygiene (45.7\%) and only one participant demonstrated good oral hygiene (Table 5 and Graph 1).

The coefficient of correlation to determine a correlation between DMFT and OHI-S index values showed values of $r=0.659$, which indicates a strong correlation between DMFT and OHI-S index values (Graph 2). If DMFT increases, OHI-S also increases.
Table 5: Overall oral hygiene status of the juvenile prisoners

\begin{tabular}{lll}
\hline Oral hygiene status & Frequency & Percentage \\
\hline Good & 1 & 1.0 \\
Fair & 48 & 45.7 \\
Poor & 56 & 53.3 \\
\hline Total & 105 & 100.0 \\
\hline
\end{tabular}

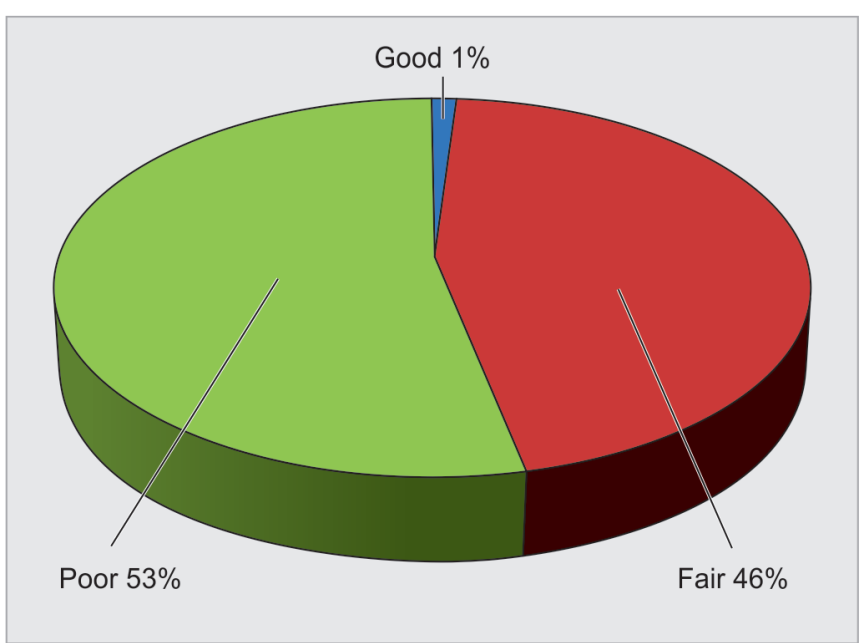

Graph 1: Distribution of oral hygiene status among the juvenile prisoners

\section{DISCUSSION}

The present study was conducted to determine the prevalence of dental caries and oral hygiene status of juvenile prisoners in Riyadh. There have been few studies carried out on the oral health status of adult prisoners in various parts of the world. ${ }^{4,7,14,15}$ The studies on juvenile prisoners are limited. ${ }^{2,13}$ To the best of our knowledge, the present 


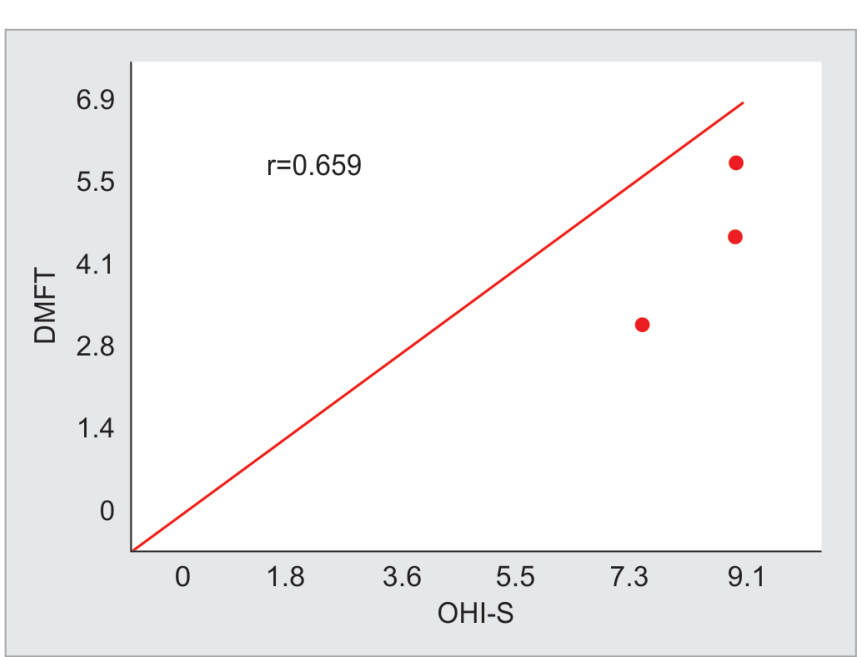

Graph 2: Coefficient of correlation between mean DMFT and mean OHI-S scores

study is the first attempt to assess prisoners' oral health in Riyadh, Kingdom of Saudi Arabia.

The outcome of the present study showed that the mean DMFT of the juvenile inmates was very high. The average DMFT for the 12- to 13-year-old population in the present study was 7.13, which was very high, compared with the average DMFT of 2.8 according to the WHO report for 12-year-olds in the Kingdom of Saudi Arabia. ${ }^{25}$ The national prevalence of dental caries and its severity in children in the Kingdom of Saudi Arabia was estimated to be approximately $80 \%$ for the primary dentition with a mean DMFT of 5.0 and approximately $70 \%$ for permanent dentition with a mean DMFT score of $3.5 .^{18}$ The mean DMFT also increased with age of the prisoners. These findings may be due to the fact that teeth in the older aged group are exposed to oral environment for a longer period of time. ${ }^{26}$ The untreated dental caries and less numbers of filled teeth accounted to much of the DMFT score among the examined juvenile prisoners. This could be attributed to inadequate prison health care services, lack of dental awareness, and differences in the diet consumption of the prisoners. ${ }^{27}$ Furthermore, the oral health services are provided only in emergency situation rather than routine checkups. This also supports the fact that the oral health status of juvenile prisoners is worse than the general population and is well supported by previous reported studies about oral health care services in prison. 2,13,15

As suggested by Al Agili, ${ }^{18}$ the dental professionals and concerned health department in the Kingdom of Saudi Arabia should bear the responsibilities in addressing the issues of high dental caries prevalence among the children. The author further stated that baseline data and good understanding of dental caries determinants are very much essential in setting up appropriate oral health goals. These goals should be aimed at improving the oral health of Saudi Arabian children.
More than $50 \%$ of the examined prisoners presented with poor oral hygiene, less than half presented with fair oral hygiene, and only one prisoner aged 12 to 13 years showed good oral hygiene. Among the measured OHI components, calculus was more prevalent among the prisoners, which were similar to the findings of the previous studies. ${ }^{2,28,29}$ The OHI-S scores for the prisoners in the present study were very high compared with the reported OHI scores for physically and mentally handicapped children in the previous studies. ${ }^{20,30,31}$ As the age increased, the OHI-S scores also increased, which could be explained by the fact that the cumulative effect of plaque and calculus increases with the age. ${ }^{2}$ The increased OHI-S with age conforms with the previous studies. $^{32}$

Our findings confirm that prisoners have an impoverished oral health status due to reasons, such as inadequate oral care facilities, lack of dental health awareness among the prisoners, absence of oral health promotion programs, and, finally, negligence from both the prison administration and prisoners. Although the juvenile prisons have dental services, the prisoners may use it only in emergency situations, such as severe pain or discomfort affecting their daily routine. In developing an oral health program for this special group, there are numerous challenges and obstacles. Possibly, it is the time for us to follow the Western countries in our approach to dental health care in prisons. Basic oral health care programs targeted at juvenile prisoners should be started immediately as most of these prisoners go back to the society after serving their sentences.

\section{CONCLUSION}

As conclusion, the juvenile prisoners had a high prevalence of dental caries and fair-to-bad oral hygiene, indicating poor oral health status. Furthermore, the study emphasizes the need for special attention from the concerned health authorities, voluntary organizations, and surrounding dental colleges in meeting the oral health needs of this group.

\section{ACKNOWLEDGMENTS}

Author would like to thank Dr Mohammed Alshehri and Dr Hassan Khan for their unconditional support during the research. Special thanks to the administration and all participants at the Malaz Juvenile Detention Center, Riyadh, Kingdom of Saudi Arabia, for their kind support during the research work.

\section{REFERENCES}

1. Siegel LJ, Welsh B. Juvenile delinquency: the core. 4th ed. Belmont, CA: Wadsworth/Cengage Learning; 2011. 
2. Agrawal A, Bhat N, Shetty S, Sharda A, Singh K, Chaudhary H. Oral hygiene and periodontal status among detainees in a juvenile detention center, India. Oral Health Prev Dent 2011;9(3): 281-287.

3. Committee on Adolescence. Health care for youth in the juvenile justice system. Pediatrics 2011 Dec;128(6):1219-1235.

4. Colsher PL, Wallace RB, Loeffelholz PL, Sales M. Health status of older male prisoners: a comprehensive survey. Am J Public Health 1992 Jun;82(6):881-884.

5. Coninx R, Maher D, Reyes H, Grzemska M. Tuberculosis in prisons in countries with high prevalence. BMJ 2000 Feb;320(7232):440-442.

6. Hotopf M, Wall S, Buchanan A, Churchill R. Changing patterns in the use of the Mental Health Act 1983 in England, 1984-1996. Br J Psychiatry 2000 May;176:479-484.

7. Lindquist $\mathrm{CH}$, Lindquist $\mathrm{CA}$. Health behind bars: utilization and evaluation of medical care among jail inmates. J Community Health 1999 Aug;24(4):285-303.

8. Naito M, Yuasa H, Nomura Y, Nakayama T, Hamajima N, Hanada N. Oral health status and health-related quality of life: a systematic review. J Oral Sci 2006 Mar;48(1):1-7.

9. Thorpe S. Oral health issues in the African region: current situation and future perspectives. J Dent Edu 2006 Nov;70:8-15.

10. Schoen MH, Freed JR. Prevention of dental disease: caries and periodontal disease. Ann Rev Public Health 1981;2:71-92.

11. Kathmandu RY. The burden of restorative dental treatment for children in Third World countries. Int Dent J 2002 Feb;52(1):1-9.

12. Sogi GM, Bhaskar DJ. Dental caries and oral hygiene status of school children in Davangere related to their socio-economic levels: an epidemiological study. J Indian Soc Pedod Prev Dent 2002 Dec;20(4):152-157.

13. Bolin K, Jones D. Oral health needs of adolescents in a juvenile detention facility. J Adolesc Health 2006 Jun;38(6):755-757.

14. Barnes GP, Parker WA, Fultz RP, Rees TD, Lyon TC Periodontal treatment requirements of recently incarcerated prison inmates. J Periodontal Res 1987 Sep;22(5):422-425.

15. Conte TG. Realistic dental care in jails and prisons: summary of proceedings. J Am Dent Assoc 1981 Mar;102(3):343.

16. Krupp LB, Gelberg EA, Wormser GP. Prisoners as medical patients. Am J Public Health 1987 Jul;77(7):859-860.

17. Nguyen TC, Witter DJ, Bronkhorst EM, Truong NB, Creugers $\mathrm{NH}$. Oral health status of adults in Southern Vietnam - a crosssectional epidemiological study. BMC Oral Health 2010 Mar 13;10:2.

18. Al Agili DE. A systematic review of population-based dental caries studies among children in Saudi Arabia. Saudi Dent J 2013 Jan;25(1):3-11.

19. Al-Ansari A. Prevalence, severity, and secular trends of dental caries among various Saudi populations: a literature review. Saudi J Med Med Sci 2014 Dec;2(3):142-150.
20. Alhazmi A, Alshinqiti I, Aloufi F, Abdulmoeen A, Waleed A, Mohammed A. Oral health knowledge, practice, oral hygiene status and dental caries prevalence among visually impaired student in Alnoor Institute of Almadinah Almunawwarah at Saudi Arabia. Int J Dent Sci Res 2014;2(6):149-153.

21. Farooqi FA, Khabeer A, Moheet IA, Khan SQ, Farooq I, ArRejaie AS. Prevalence of dental caries in primary and permanent teeth and its relation with tooth brushing habits among schoolchildren in Eastern Saudi Arabia. Saudi Med J 2015 Jun;36(6):737-742.

22. Mahrous MS, Bhayat A, Hifnawy T, Bakeer H, Mohamed SA. Can the prevalence of dental caries be used as an indicator of the quality of dental services? A cross-sectional study among children in Almadinah Almunawwarah, KSA. J Taibah Univ Med Sci 2016 Feb;11(1):41-45.

23. World Health Organization. Oral health surveys basic methods. 5th ed. Geneva: World Health Organization; 2013. p. $42-47$.

24. Greene JC, Vermillion JR. The simplified oral hygiene index. J Am Dent Assoc 1964 Jan;68:7-13.

25. World Health Organization. Region specific weighted DMFT among 12 year old, 2014. Available from: https:/ / www.mah. se/CAPP/Country-Oral-Health Profiles/EMRO/.

26. Sharma A, Bansal P, Grover A, Sharma S, Sharma A. Oral health status and treatment needs among primary school going children in Nagrota Bagwan block of Kangra, Himachal Pradesh. J Indian Soc Periodontol 2014 Nov-Dec;18(6): 762-766.

27. Reddy V, Kondareddy CV, Siddanna S, Manjunath M. A survey on oral health status and treatment needs of life-imprisoned inmates in central jails of Karnataka, India. Int Dent J 2012 Feb;62(1):27-32.

28. Mahesh Kumar P, Joseph T, Varma RB, Jayanthi M. Oral health status of 5 years and 12 years school going children in Chennai city-an epidemiological study. J Indian Soc Pedod Prev Dent 2005 Mar;23(1):17-22.

29. Varenne B, Petersen PE, Ouattara S. Oral health status of children and adults in urban and rural areas of Burkina Faso, Africa. Int Dent J 2004 Apr;54(2):83-89.

30. Cardoso AM, Gomes LN, Silva CR, Soares Rde S, Abreu MH, Padilha WW, Cavalcanti AL. Dental caries and periodontal disease in Brazilian children and adolescents with cerebral palsy. Int J Environ Res Public Health 2014 Dec 29;12(1):335-353.

31. Jain M, Mathur A, Sawla L, Choudhary G, Kabra K, Duraiswamy P, Kulkarni S. Oral health status of mentally disabled subjects in India. J Oral Sci 2009 Sep;51(3): 333-340.

32. Subrata S, Subrata S. Prevalence and severity of dental caries and oral hygiene status in rural and urban areas of Calcutta. J Indian Soc Pedod Prev Dent 1996 Mar;14(1):17-20. 